\title{
ESCREVER O PASSADO, PENSAR O PRESENTE: HISTORIADORES E A BATALHA PELA MEMÓRIA DA DITADURA MILITAR CHILENA ${ }^{1}$
}

Fernanda Luiza Teixeira Lima ${ }^{2}$

\author{
O golpe de 1973: mudanças de interpretação e sentidos na historiografia chilena até \\ 1990
}

Em 11 de setembro de 1973, a via chilena para o socialismo ${ }^{3}$, presidida pelo então presidente Salvador Allende (UP), depois de mil dias no governo, encontrou sua derrota. Seu fim não foi somente o término de um processo pacífico institucional de reforma social, mas também marcou o esgotamento dos modelos políticos e culturais da política de esquerda chilena. Este episódio marcou não somente a história da vida política do país como também a historiografia do período. O desenlace da Unidad Popular (UP) provocou efeitos diretos sobre a historiografia chilena. Instigou a reflexão sobre o papel da história e, principalmente, implicou o questionamento sobre qual ao lugar dos historiadores diante de tais acontecimentos.

O governo de Pinochet adotou uma postura forte e determinante no tocante às reações contrárias ao seu governo logo após o golpe. A rapidez da Junta Militar evidenciava que, embora não definido, nos primeiros momentos, se o caráter da ditadura que se instalava era refundador ou restaurador, a atitude golpista vinha por em xeque a atuação política dos partidos. Podemos dizer que essas ações ditatoriais no Chile induziram a um governo apolítico, que se apoiava na justificativa de manter a unidade nacional e a ordem no país. Para garantir essas medidas, o governo utilizou suas instituições (o exército nacional e a polícia), criando os grupos militares de repressão e extermínio e a Dirección de Inteligencia Nacional (Dina), uma comissão especializada para atuar em investigações e prisões dos inimigos do regime e prevenir as "ações comunistas".

A geração de historiadores da década de 1970 passou por uma crise de paradigmas que teve como consequência central o banimento de seus principais intelectuais pelo regime militar de Augusto Pinochet. A partir de 1975, os pensadores exilados iniciaram, em seus trabalhos teóricos, uma etapa de reflexão a respeito da história chilena. Tais estudiosos começaram um percurso de avaliação sobre alguns pontos-chaves da história política do Chile, como a experiência da Unidade Popular de Salvador Allende, a definição e a profundidade da ruptura alcançada pela ditadura militar $e$ a busca por alternativas viáveis para a situação política que era vivenciada naquele momento. Como assinalou o historiador Gabriel Salazar, sobre quem trataremos mais à frente, a história, se converteu em "un inesperado polo de convergencia intelectual y de reagrupación cultural, y al mismo tiempo, en una matriz de la cual surgieron diversos grupos de investigadores e instancias de reproducción común".

Diante da nova conjuntura e destituídos de muitos de seus parâmetros históricos e sociais, os historiadores chilenos foram obrigados a experimentar um período de atualização e autoexame dos caminhos percorridos na disciplina. Embora possamos marcar diversos eventos de natureza violenta na

\footnotetext{
${ }^{1}$ Agradeço ao professor Luiz Estevam de Oliveira Fernandes, da Universidade Federal de Ouro Preto, que muito contribuiu para a construção deste artigo durante a minha escrita da dissertação.

${ }^{2}$ Doutoranda em História pela Universidade Estadual de Campinas. E-mail: fernandaluizatlima@yahoo.com.br

${ }^{3}$ Enquanto esteve no poder Allende estabeleceu algumas mudanças na economia chilena: nacionalizou os bancos, avançou no projeto de redistribuição de terras com a reforma agrária e tornou nacional parte das minas de cobre que estavam sob o domínio de indústrias estrangeiras. Essas medidas enquadravam-se dentro de seu projeto político conhecido como "via chilena para o socialismo", programa que previa a transição ao socialismo no país de forma pacífica e com a garantia das normas constitucionais já estabelecidas, isto é, rechaçava a utilização do emprego da força militar para a concretização do seu plano. C.f. LIMA, Fernanda Luiza Teixeira. Batalhas pela memória: verdade, reparação e justiça nas narrativas historiográficas e fílmicas sobre a ditadura chilena (1973- 2015). 2015. 145 f. Dissertação (Mestrado em História) - Instituto de Ciências Humanas e Sociais, Universidade Federal de Ouro Preto, Mariana, 2017. Disponível em: http://www.repositorio.ufop.br/handle/123456789/9082

${ }^{4}$ SALAZAR, Gabriel. Historiografía y Dictadura en Chile: búsqueda, dispersión, identidad. In: La Historia desde abajo y desde dentro. Santiago: Facultad de Artes, Universidad de Chile, 2003, p. 106.
} 
história do Chile, foi a primeira vez ao longo do século XX, que houve um estado militar autoritário no poder, reconfigurando toda a vida política e as linhas de pensamentos sociais do país. A quebra imposta pela ditadura foi profunda, fazendo com que as novas interpretações históricas frequentemente estabelecessem o antes e depois do golpe para entender como esse acontecimento teria sido possível.

Nesse sentido, inaugurou-se, naquele período, novas proposta para a construção da memória da experiência de repressão, das quais destacamos as três principais: a primeira seria a historiografia oficial, isso é, legitimada pelo governo militar, basicamente seus princípios foram calcados pelas ideias nacionalistas conservadores do começo do século XX. Como exemplo, citamos o trabalho do historiador da Universidade Católica, Mario Góngorra, que se converteu a princípio em um dos pilares ideológicos do regime de Pinochet. Em 1976, recebeu o Prêmio Nacional de História ${ }^{5}$, pelo Ministério da Educação, por elaborar uma "história nacional" e produzir textos que dessem conta de resolver os problemas históricos pelos quais o Chile passava. Como mostra a declaração do ministro da Educação, contra almirante Arturo Trancoso Daroch, publicada no periódico Las ultimas Noticias, em 1976, sobre o reconhecimento do historiador: "sus estudos acerca de la Historia Nacional son usados em centros universitários extranjeros: algunos son modelos de una aproximación nueva de los problemas históricos nacionales en el acontecer de um horizonte próprio de la historia universal"6. Apesar de, inicialmente, justificar e acreditar ser necessário o controle da política do país pelos militares, Gongórra começou a se distanciar do governo ao compreender que a normalização democrática não ocorreria como imaginava. Em sua obra Ensayo histórico sobre la noción de Estado en Chile en los siglos XIX y XX (1981) Góngorra tentou identificar os problemas ou motivos que levaram ao fim do governo de Allende e atribuiu à incompetência e ao dever basilar do Estado de formar (negligenciado por Allende), ao mesmo tempo em que adverteu sobre o perigo das políticas comunistas. No mesmo trabalho, o autor ainda alertava, mesmo que discretamente, acerca dos problemas que a política neoliberal do regime militar de Pinochet poderiam trazer ao país. Dessa maneira, apesar de algumas ressalvas, Góngorra legitimava os novos rumos políticos do país e compreendia que a instalação da Junta Militar seria um "remédio" necessário à "saúde" do Chile. ${ }^{8}$

Para o pesquisador, a via chilena nunca teria operado dentro dos limites legais da democracia, pois era totalmente paradoxal e inconcebível ter democracia e socialismo em um mesmo modelo político, uma vez que o fim único da UP seria, de acordo com o historiador, estabelecer a ditadura do proletariado no país. Desse modo, pensando em Góngorra como representante de uma historiografia mais conservadora, o que deveria prevalecer no momento seria a formulação de uma história oficial que priorizasse em seus textos a justificativa e a defesa do reestabelecimento da ordem no Chile. Essa vertente também deveria apoiar a nova política econômica liberal e ensejar o combate ao marxismo, de tal modo que se elucidasse que a opção pelo golpe militar fora a escolha justa e necessária para por o país em seus rumos.

Dessa geração inicial, apresentamos com mais detalhes as principais teses do historiador Gonzalo Vial Correa ${ }^{9}$. Representante de um nacionalismo mais doutrinário, o historiador foi apoiador ativo da instalação e da legitimação dos militares no poder. Participou, por exemplo, da elaboração do "Libro Blanco" 10 , escrito e publicado pela Secretaria Geral de governo. Nessa obra,Vial ajudou a fundamentar uma suposta teoria a respeito da existência de um "Plano Zeta" que teria seria planejado por Allende para derrubar as Forças Armadas Chilenas. O historiador ocupou o cargo de ministro da Educação em 1978, durante um breve período de oito meses. Vial decidiu sair do governo devido ao antagonismo que tinha com grupos nacionalistas laicos próximos ao general Pinochet. ${ }^{11}$

Em uma perspectiva mais acadêmica e que pudesse ajudar a fundamentar e revelar a "verdade

\footnotetext{
${ }^{5}$ Informações retiradas do documento: PROFESOR Mario Góngora ahora es otro inmortal. Las Últimas Noticias, Santiago, 26 jul. 1976.

${ }^{6}$ GÓNGORA, Mario. Ensayo histórico sobre la noción de Estado en Chile. Editorial Universitaria. [S.1.: s.n.], 2010.

${ }^{7}$ GÓNGORA, Ensayo histórico...

${ }^{8}$ GÓNGORA, Ensayo histórico..., p. 23.

${ }^{9}$ Gonzalo já demonstrava insatisfação quanto ao governo Allende em 1970 por meio de suas publicações em artigos das revistas: Qué Pasa e Portada, as quais era cofundador.

${ }^{10} \mathrm{O}$ livro encontra-se disponibilizado no sítio de Centro de Estudios "Miguel Enríquez": Archivo Chile. Disponível em: http://www.archivochile.com/Dictadura militar/doc sobre dm/DMdocsobre0005.pdf Acesso em: 30 jun. 2015.

${ }^{11}$ CORREA, Gonzalo. Historia de Chile (1891-1973). Santiago de Chile: Editorial Portada, 1981. 
oficial' sobre o governo da Unidad Popular, Vial iniciou, em 1981, a edição de sua coleção História de Chile. Em seis volumes, o ex-ministro procurou mapear as origens da crise chilena durante o período de 1891-1973. Sua principal tese era que a ruptura política ocorreu devido à privação da unidade nacional, condição para a manutenção e o equilíbrio do país. Para o autor, a unidade nacional deve ser entendida como "um sistema de valores fundamentais único", como teria ocorrido, segundo o autor, na propagação e na expansão do "catolicismo de raiz hispânica", o que permitiu unir o Chile em uma só nação. Como reitera o autor: "(...) un país no puede vivir sin la unidad nacional. Si la pierde andará tumbos hasta que la recomponga "sobre las antiguas o sobre nuevas bases, como requisito indispensable para volver a tomar su tranco histórico". ${ }^{12}$

Ou seja, na avaliação de Gonzalo Vial, o país encontrava-se numa decadência profunda por ter perdido sua unidade nacional antes mesmo de Allende chegar ao poder; por isso, era urgente encontrar um "novo rumo histórico", sob antigas ou novas bases, ainda que fosse sob aspectos "injustos ou dolorosos". Em "Decadência, consenso, y unidad nacional", artigo publicado em $1984^{13}$, acusado de pensar a sociedade chilena sob uma perspectiva reducionista e religiosa, o autor se defende e tenta mostrar que sua ideia não era vincular uma nova unidade nacional aos caminhos do fenômeno do catolicismo hispânico, como muitos teriam analisado, mas lhe parece claro que, apesar de tudo, a unidade nacional no futuro ocorreria cerceada de fortes valores "cristãos, de tradição católica e éticos". ${ }^{14}$

Nesse sentido, a interligação desses conceitos supõe basicamente o que ele denomina de "el consenso", que representa a reunião de um conjunto de ideias universais sobre temas básicos que poderiam ser partilhados pela maioria dos chilenos. Tais valores deveriam ser intocáveis para garantir, de fato, a dita unidade. Compondo, assim, um fundo quase natural no qual coubessem "projetos históricos distintos em uma unidade nacional". Sobre o conceito do 'consenso', Vial o define nos seguintes termos:

(...) Son ideas de patria, de nacionalidad, de tradición histórica y cultural, de familia, de educación, de propiedad, de juridicidad, de inalienables derechos de la persona humana y de las minorías, etc. Ideas que el tiempo, las razas progenitoras, la cultura, la Historia, han entretejido con el ser de Chile y con la idiosincrasia de los chilenos, de tal modo que no puede desarraigarlas ninguna ley, ninguna ideologia, ninguna revolucion. . . son ya nuestra naturaleza. ${ }^{15}$

A ideia de unidade nacional e os "consensos" como chave para explicar tudo foram, em geral, o embasamento teórico do autor e se enquadravam em um projeto de uma história global e universal que pudesse abarcar e conferir todos os sentidos da sociedade chilena naquele momento. Em suma, como podemos avaliar, essa interpretação esteve muito presente nos textos dos historiadores ou de outros intelectuais da época que procuraram legitimar o regime militar como a única saída para a desorganização que assolava o país. A vitória dos militares no poder representava a salvação e a reintegração da moral e da unidade do povo chileno. Ou, como apresenta Júlio Pinto ${ }^{16}$, uma simbologia do regime que poderia ser análoga ao que representou o ano de 1973 para a história chilena seria 1810, o ano da independência do país. Isto é, a restauração da ordem pelos militares teria significado, para alguns historiadores, um segundo marco de fundação nacional.

Não é por acaso que o ex-ministro e intelectual Diego Portales, conhecido como organizador da República chilena e por seus ideais políticos de defesa de um governo forte, centralizador e, por vezes, autoritário a fim de manter a ordem e a unidade do país, converteu-se em referências obrigatórias para os textos desses historiadores. De acordo com Pinto, isso fez com que as interpretações históricas nas primeiras décadas do golpe voltassem a consagrar a "escuela nacionalista-conservadora" do início do século XX em caráter hegemônico e oficial. ${ }^{17} \mathrm{Em}$ uma vertente diferente, mas ainda não de oposição radical ao que representou a "via chilena no poder", destacamos os trabalhos iniciais de Sergio

\footnotetext{
${ }^{12}$ CORREA, Historia de Chile..., p. 159.

${ }^{13}$ CORREA, Historia de Chile...

${ }^{14}$ CORREA, Historia de Chile..., p. 160.

${ }^{15}$ CORREA, Historia de Chile..., p. 161.

${ }^{16}$ PINTO, Julio Vallejos; ARGUDÍN, María Luna. Cien años de propuestas y combates. La historiografía chilena del siglo XX. México: Universidad Autónoma Metropolitana, Unidad Azcapotzalco, 2006.

${ }^{17}$ PINTO; ARGUDÍN, Cien años de propuestas y combates, p. 43.
} SÆCULUM - REVISTA DE HistóRIA[39]; João Pessoa, jul./dez. 2018. 
Villalobos (1980) sobre o período. Contrário às ideias do governo da Unidad Popular, o historiador, após o novo regime instaurado, obteve mais espaço na academia, que estivera durante algum tempo destinada mais aos trabalhos "esquerdistas", segundo o mesmo.

Para Villalobos, o passado tem que ser entendido dentro de sua totalidade, assim como afirmara Vial, não seria possível ter uma compreensão clara do que foi o golpe se o enfoque estiver apenas repercutido durante a quebra pela ditadura. Sendo assim, o objeto de estudo da pesquisa histórica deveria se redefinir para incluir "grandes processos" e as "áreas mais profundas do evento". Defensor de uma "história total", supostamente a mesma desenhada pelo historiador francês Fernand Braudel (1958), na Escola dos Annales, Villalobos apontava a "nação" chilena como verdadeira protagonista de sua História. Como define em sua introdução na obra Historia del Pueblo chileno ${ }^{18}$, a respeito do ofício do historiador:

Una y otra vez el hombre incursiona en el pasado buscando respuesta a los problemas que le inquietan. Cada época es ruptura de horizontes y conquista de cumbres ignoradas, desde cuyas alturas se contempla la historia con perspectiva diferente. Nuevas alturas significan mayor visión y nuevas interrogantes, que enfrentan al hombre consigo mismo y le llevan, en desesperante esfuerzo, a indagar en los viejos tiempos el sentido de su trayectoria, porque ésa es su única experiencia. El presente es siempre inabarcable e incierto y el futuro no es más que una esperanza surgida entre temores. ${ }^{19}$

Podemos dizer que o esforço de atualização dentro desses grupos de historiadores possuía, em primeiro lugar, um sentido ou quase um dever de legitimar a ordem econômica, política e social conforme perspectivas de grandes estruturas ao tratar e investigar os acontecimentos da experiência da ditadura com grande rigor metodológico, buscando a explicação para ele sua existência. Entretanto, o avançar da permanência militar no poder e o fortalecimento 'estatal' da ditadura levaram alguns desses historiadores a assumirem outro discurso, até mesmo de oposição e denúncia do caráter centralizador e repressor do regime. É interessante pensar que as diferentes interpretações apresentadas até o momento buscam um tipo de caráter nacional que possa caracterizar a história chilena. É como se encontrar um tipo de história com vocação nacional pudesse fazer com que houvesse uma história capaz de dar conta das diversas identidades chilenas e das histórias mais profundas do país.

Em campos opostos do que foi apresentado, teríamos o nascimento de uma nova história social. Contrária à primeira corrente, os historiadores que se opuseram ao novo governo instaurado se viram, obrigados a trabalhar na clandestinidade ou acabaram experimentando as prisões, as torturas $e$ o exílio. Com uma proposta de recuperar e desenvolver as histórias locais chilenas e as lutas populares, a inauguração de um novo campo historiográfico, conhecido como "Nueva Historia" tinha como um de seus principais postulados a necessidade de analisar os processos econômicos e sociais desde uma perspectiva cultural "desde abajo y "desde de dentro". A ideia era inaugurar uma disciplina que atravessasse as fronteiras da dimensão acadêmica, o que será melhor apresentada no próximo tópico.

\section{Os de afuera e os de dentro: Novas perspectivas da Nueva Historia chilena}

Seguindo o recorte interpretativo da historiografia na ditadura e sobre o que representou a ruptura na disciplina após 1973, temos, ainda, a reinauguração dos trabalhos dos historiadores de orientação mais próxima à esquerda ou daqueles que se opunham frontalmente ao novo regime político de Pinochet. A maioria das investigações históricas desses intelectuais abordou grupos específicos, como a história dos sindicatos, o movimento operário, ou as poblaciones, fruto da proposta metodológica de recuperação da memória popular. Ou, conforme entendiam os autores, esses grupos representavam a maioria que lutou a favor da via chilena ao socialismo e que tentava se reorganizar após o golpe instaurado. Muitos historiadores ligados a essa linha de investigação tiveram que operar na clandestinidade devido à repressão imposta pelo regime.

\footnotetext{
${ }^{18}$ VILLALOBOS, Sergio; RETAMAL, Avila Julio; SERRANO, Sol. Historia del pueblo chileno. Santiago: Instituto Chileno de Estudios Humanísticos, 1980.

${ }^{19}$ VILLALOBOS; RETAMAL; SERRANO, Historia del pueblo chileno..., p. 12.

236 SÆCUlUM - REvista DE HistóRIA [39]; João Pessoa, jul./dez. 2018.
} 
Dessa época inicial, destacamos os autores Eduardo Devés, Ximena Cruzat e Luis Emilio Recabarren, os quais se dedicaram a investigar as origens do movimento obrero e do pensamento socialista chileno. Uma das obras mais debatidas e comentadas do período foi Los que van a morir te saludan, de Devés. O trabalho foi publicado em 1988 e narra a história do massacre ocorrido em 1907 na Escola Santa María Iquinique ${ }^{20}$. Ainda que essa batalha do início do século XX não tenha ligação direta com as explicações sobre a origem do golpe de 1973 ou com sua denúncia, o trabalho de Eduardo Devés inaugurou um novo caminho metodológico ao incorporar a história dos operários do norte salitreiro. O autor rompe com uma narrativa de eixo vocacional da nação e mostra dissensões, rupturas, vozes sufocadas e rebeldes. O Chile não era uno e foi forçado a fórceps para sê-lo.

Mesmo demonstrando ser possível exercer e propor novas avaliações ao curso da disciplina de dentro do próprio Chile, o grupo de exilados era muito maior e desenvolvia propostas análogas no exterior. Ao estabelecerem contato com outras possibilidades de linhas teóricas na Europa, muitos historiadores incorporaram novas formas para compreender a história do país. Houve, predominantemente, a incorporação de debates da Escola dos Annales e da historiografia marxista que vinha sendo desenvolvida após o fim da Segunda Guerra. Como avaliou a historiadora brasileira Adriana Vidal Costa em análise sobre o impacto do exílio aos historiadores na América Latina durante a ditadura:

Os exílios criam e intensificam redes de comunicação entre intelectuais e ampliam o conhecimento das singularidades de cada região. A história da América Latina tem sido, desde o século XIX, marcada pelo exílio, seja ele forçado ou voluntário, seja para países do Continente Americano ou para a Europa. ${ }^{21}$

É válido recordar também que o estudo dos movimentos populares no Chile já ocorria com força com base nos trabalhos durante as décadas de 1950, 1960 e início dos anos 1970 pelos historiadores marxistas clássicos, como Julio César Jobet, Marcelo Segall, Hernán Ramírez Necochea, Jorge Barría Serón e Enrique Reyes. Apesar de suas diferenças quanto à escolha de seus objetos de estudo, esses historiadores adotaram a teoria marxista como marco teórico para suas análises e referência para pensar o papel da história, facultando um lugar central ao proletariado mineiro e industrial. Como comentou o historiador Sergio Grez a respeito da incorporação dessas novas análises: "el rechazo a la 'interpretación alucinantemente estructuralista' de los procesos históricos, ha llevado a algunos historiadores sociales a postular (sino en la teoría, al menos en los hechos) una historia de 'los de abajo"". 22

Sendo assim, no contexto da ditadura militar, foi formada a oficina Nueva História, pela Associação de Historiadores Chilenos, no ano de 1980, em Londres. A instituição reuniu historiadores chilenos que atuaram no exílio, tais como: Leonardo León, Luis Ortega e Gabriel Salazar, por intermédio de outros colaboradores que permaneceram no Chile, como os historiadores Pedro Milos, Mário Garcés e outros estudiosos da Universidade Católica chilena, que editaram e publicaram a revista Nova História entre os períodos de 1981 a 1989, convertendo-se, como bem assinalou Pinto, em um verdadeiro espaço entre "los de afuera" e "los de dentro"23.

Podemos dizer que, entre 1973 e os anos iniciais da década seguinte, a primeira geração de historiadores consistiu em recordar o passado recente da UP, no sentido de autocrítica política e de busca das razões da derrota. Esses grupos ocuparam um lugar "fundacional" para a elaboração dos anos seguintes da Nova História, ou como Gabriel Salazar sintetiza:

\footnotetext{
${ }^{20}$ DEVÉS, Eduardo. Los que van a morir te saludan, Historia de una masacre. Escuela Santa María de Iquique, 1907. Santiago: Lom Ediciones, 1997.

${ }^{21}$ COSTA, Adriane Vidal. Intelectuais, política e literatura na América Latina: o debate sobre revolução e socialismo em Cortázer, García Márquez e Vargas Llosa (1958-2005). Tese 320(Doutorado em História) - Universidade Federal de Minas Gerais, Belo Horizonte, 2009.

${ }^{22}$ GREZ TOSO, Sergio. Historia, política y ciudadanía en el Chile actual: Problemas y desafíos para la historiografía crítica. Rev. austral cienc. soc., n. 21, p. 137-146, 2011. Disponível em: http://mingaonline.uach.cl/scielo.php?script=sci_arttext\&pid=S0718-17952011000200007\&lng=es\&nrm=iso. Acesso em: 25 ago. 2015.
}

${ }^{23}$ GREZ TOSO, Historia, política y ciudadanía en el Chile actual, p. 52. 
[...] en el Reino Unido, un grupo de historiadores exiliados (encabezados por Leonardo León, Luis Ortega y el que suscribe) intentaron, desde 1981, echar las bases de una "nueva historia", que superara las limitaciones de la historiografía conservadora, marxista y academicista, tanto en lo que se refiere a su relación con los enfoques y métodos de las ciencias sociales, al modo de construir los conceptos y al enfoque teórico, a su inserción activa en los debates contemporáneos, como también a su capacidad de integrar las preguntas de la base social. Esta orientación permitió ensanchar el horizonte temático (se incluyó el problema del desarrollo industrial, el movimiento histórico de las etnias indígenas, la crítica histórica de las teorías del desarrollo y la dependencia, etc.), incorporar un panel más variado de metodologías, incrementar la capacidad crítica de la disciplina e incorporar numerosos cientistas sociales de la comunidad internacional al trabajo de reconstrucción del pensamiento histórico y político latinoamericano. ${ }^{24}$

A nova corrente historiográfica, então, teria nascido na chamada "geração de 1985", tendo como marco o importante o processo de luta e organização popular - as protestas ${ }^{25}$ - contra a ditadura. Isso facilitou a circulação $e$ a recepção dos novos caminhos da historiografia chilena, trilhando um roteiro desde a busca dos culpados (primeira etapa) à reconciliação (segunda etapa). Uma das grandes referências dessa redefinição da historiografia chilena, já citado diversas vezes ao longo deste texto, é o historiador Gabriel Salazar Vergara, ex-integrante do MIR (Movimiento de Izquierda Revolucionaria) entre 1970 e 1973. Após o golpe, ele foi preso e conduzido ao centro de detenção Villa Grimaldi; mais tarde, em 1976, foi exilado para o Reino Unido, onde se formou doutor na Universidade de Hull $e$ ajudou a fundar o grupo da Nueva Historia Social.

Como mencionado, em 1985, com o enfraquecimento da ditadura de Pinochet devido às "protestas" e por meio das pressões internacionais, Salazar conseguiu regressar ao Chile, e sua tese de doutorado Labradores, Peones y Proletarios $^{26}$ foi publicada no país no mesmo ano. O trabalho apresentou as principais ideias dessa nova proposta de uma "ciência do povo" ou como intitula a "nova história social".

Rompendo com a linha de pensamento teleológico e linear da história, Salazar baseia-se na convicção de que a sociedade popular deve ser estudada como se apresenta naturalmente e não por meio de sua dimensão política. Para compreender em sua essência o pensamento e o comportamento dessa sociedade, devem ser observados aspectos da vida cotidiana desses peones e proletários. $\mathrm{O}$ autor tenta privilegiar, então, seu olhar para as condições de vida desses grupos ao analisar suas relações sociais, culturais e outros elementos que pudessem ir além das estruturas econômicas que circundavam essas comunidades. ${ }^{27}$

Embora Salazar reconhecesse as "teorias de classes populares" da escola marxista, o golpe de 1973 acabou colocando em xeque as velhas tendências teóricas marxistas, que atribuíam uma evolução quase natural do pensamento político do movimento popular que culminasse em sua vitória com a instauração do socialismo. Logicamente, com o golpe e o enfraquecimento da esquerda, obrigatoriamente, houve um reposicionamento da história popular na historiografia, como explica o estudioso em sua tese:

(...) la ruptura histórica de 1973 quebró la espina dorsal de varias tendencias históricas que habían cobijado el desarrollo del primer movimiento popular chileno. Eso implicó la modificación del basamento fundamental sobre el que se construyeron los sistemas teóricos de la fase 1948-73. Hoy, las clases populares parecen reclamar no sólo la renovación del impulso científico inaugurado por J. C. Jobet en 1948, sino también la apertura de los esquemas de análisis que, un tanto rígidamente, habían prevalecido durante esa fase. ${ }^{28}$

\footnotetext{
${ }^{24}$ SALAZAR, Historiografía y Dictadura en Chile..., p. 111-112.

${ }^{25}$ As Protestas foram a principal reação popular contra o governo de Augusto Pinochet. A partir de 1983, ainda sob o impacto da crise econômica, o país ingressou em uma conjuntura favorável às oposições, representada pela ofensiva de movimentos sociais, associações de bairro, sindicatos, setores da igreja e partidos semiclandestinos que passaram a reclamar a volta à democracia. Até 1986, ocorreram inúmeras manifestações de oposição ao regime que podem ser incluídas no ciclo das Protestas.

${ }^{26}$ SALAZAR, Historiografía y Dictadura en Chile...

${ }^{27}$ SALAZAR, Historiografía y Dictadura en Chile..., p. 44

${ }^{28}$ SALAZAR, Historiografía y Dictadura en Chile..., p. 2. 
Dessa forma, a "sociedade popular" deveria ser estudada como se apresentava "naturalmente", desde sua formação (época colonial) e na crise do século XIX, dentro de seus espaços internos de convivência; abandonando, por ora, as "causas estruturais" e fixando a análise em sua própria "experiência social". Conforme o autor salienta:

desarrollar la ciencia 'del pueblo' puede ser un objetivo más complejo y mutante de lo que parece a primera vista. Así, por ejemplo, si se adopta mecánicamente el materialismo histórico, puede ocurrir -como ha ocurrido- que, por dar curso forzoso a determinados procedimientos metodológicos, se conduzca la investigación por un camino lateral al planeado originalmente. Tal ocurre cuando, pongamos por caso, al intentar reducir la multiplicidad real-concreta a un número manejable de categorías simples y abstractas, se desechan conceptos concretos o inclusivos (como 'clases populares' o 'pueblo') para trabajar solo los que son esenciales o unívocos (como 'proletariado industrial' o 'clase' para sí). O cuando, por dar plena vigencia al imperativo gemelo de totalización analítica, se diluye la historia existencial de las masas populares en la historia esencial del capitalismo nacional o internacional. ${ }^{29}$

Alinhado às novas propostas da nova história, o historiador Sergio Grez, contemporâneo de Salazar e também exilado político na época, corrobora a importância da obra do autor, porém, critica o alijamento da discussão política e dos efeitos políticos da nação sobre o sujeito nos textos de Salazar.

Sin reducir lo social o los movimientos sociales a sus manifestaciones y representaciones políticas, la política y lo político pueden ser el campo por excelencia en el que sujetos colectivos que sólo han tenido existencia sociológica (como el artesanado del siglo XIX o la clase obrera de comienzos del siglo XX), devienen sujetos históricos en búsqueda de identidad y autonomía. Esto es posible porque la política no es sólo ni principalmente el terreno contaminado por las influencias de la elite y del Estado; la política es por antonomasia un campo privilegiado de decantación y defensa de los intereses de las clases y grupos sociales. ${ }^{30}$

Desse modo, na tentativa de subverter a lógica da subjugação do povo ao Capital e resgatar a historicidade do "sujeito popular", Salazar rejeita a ideia de uma "unidade histórica" e muito menos a possibilidade de uma "unidade nacional" como aquela descrita e defendida por Gonzalo Vial. Ainda que para o autor:

la historicidad del 'pueblo-nación' consiste en la auto-manifestación del 'espíritu nacional', el ámbito de su resonancia no es el espacio interior mismo de la nación, sino aquel donde se proyectan otros pueblos-naciones: el de la historia universal. Pues la historia nacional es, en ultimo análisis, extravertida. Si el individuo está trascendido por el desenvolvimiento del 'espíritu nacional', éste lo está, a su vez, por "el sentido" de la historia universal. ${ }^{31}$

Apesar de o estudioso não fazer uma crítica teórica dos conceitos de "povo" e "nação", ele os entende como referenciais estáveis. O primeiro seria um sujeito histórico indivisível. Em outras palavras, não existiria um "povo mais consciente e outro menos consciente". Já "nação" seria um coletivo social diferenciado, que tem consciência própria; nesse sentido, a utilização do seu termo alude a um sentimento comum de identidade.

O encontro $e$ a investigação da vida popular estariam, assim, resgatando a historicidade $e$ "somando as massas populares", sem excluí-las do processo e, ainda, possibilitando uma maior "verdade" sobre esses sujeitos históricos. De modo geral, o programa da "nova história social chilena" deveria ir ao encontro da historicidade dos diversos grupos e das classes que se inter-relacionam na sociedade chilena, em especial aquelas que ficaram, por muito tempo, alijadas da história, o que seria

\footnotetext{
${ }^{29}$ SALAZAR, Historiografía y Dictadura en Chile..., p. 2-3.

${ }^{30}$ GREZ TOSO.S. Escribir la historia de los sectores populares. ¿con o sin política incluida? [S.1.]: Universidad de Chile, v. 44, 2005.

${ }^{31}$ SALAZAR, Historiografía y Dictadura en Chile..., p. 6. 
o espectro popular. A ideia seria fazer uma história "desde de abajo" que abarcasse não apenas os líderes ideológicos do conjunto popular, mas também desse atenção maior às especificidades do sujeito. Essa nova forma de pensar a história, representada pela obra de Salazar em nosso trabalho, caracteriza-se uma boa síntese do que foi a proposta fundamental desse grupo.

Por fim, o período militar representou, para a historiografia chilena, uma experiência ambivalente. Entre os grupos mais conservadores, vimos um esforço por parte dos historiadores em entender as origens do golpe e, até mesmo, em justificar as ações da Junta Militar como a única saída possível para o país naquele momento, reunidos nos textos de Mario Góngorra e Gonzalo Vial. Por outro lado, acompanhamos as perspectivas da "nova história chilena" com base nos textos do fundador Gabriel Salazar. Essa corrente buscou "restaurar o conjunto dos setores explorados e oprimidos" no centro da perspectiva historiográfica. Segundo os historiadores dessa linha, a história deveria ser "liberada" da hegemonia das estruturas e dos "aprioris" ideológicos; manifestando, assim, a necessidade de una "historia desde abajo" e "ampliação da visão sobre o desenvolvimento do movimento popular no Chile". ${ }^{32}$

Com base em tais paradigmas, podemos observar alguns desdobramentos de natureza política $e$ metodológica para a historiografia do período. A primeira observação diz respeito às leituras produzidas após o fim da experiência chilena que se organizaram, conforme o historiador Alberto Aggio, por meio de recortes interpretativos. No primeiro momento, os textos estiveram concentrados em definir o que foi a revolução de Allende. As abordagens dos historiadores também estiveram fortemente marcadas pela polaridade ideológica; por isso. eram comuns réplicas e tomadas de posições políticas nos textos ${ }^{33}$. A historiografia no período atua, portanto, como "instrumento de mudança", e sua proposta metodológica seria a de resgatar as origens do evento e entender como isso teria sido possível no país.

\section{Batalhas pelas memórias do passado militar chileno na historiografia: 1990 - 2015}

Com o término do governo Pinochet e a recuperação da democracia decidida em plebiscito em 1988, inaugurou-se um novo período para a historiografia chilena. Com o fim da censura e da repressão àqueles que se opunham ao regime, muitos historiadores que ainda estavam no exílio puderam voltar e, ao lado de seus colegas também livres de operar na clandestinidade, recuperaram seus espaços de debate e reflexão fechados ao longo de dezessete anos de regime.

O novo ciclo permitiu, então, não apenas o aprofundamento das propostas metodológicas que já estavam sendo realizadas durante o período, como também abriu espaço para a realização de um balanço historiográfico daquilo que foi produzido. Desse modo, narrar abertamente sobre o que significou a experiência da ditadura chilena resultou na produção de novas abordagens históricas além da incorporação de novas perspectivas teóricas. Nesse aporte, um dos efeitos na disciplina foi a intensa valorização da memória nas pesquisas. Mais do que uma simples ferramenta, após o estado de exceção pelo qual passou o Chile, a memória tornou-se um laço fundamental à história por assegurar a continuidade temporal de uma experiência. Segundo a crítica literária argentina Beatriz Sarlo ${ }^{34}$, estamos falando do que se chamou nos anos 1970 e 1980 de giro linguístico ou guinada subjetiva. Essa perspectiva reivindica o esfacelamento do passado trazido pelas "operações de apagamento" das correntes pós-modernas contemporâneas (que, paradoxalmente, trazem em si um afã preservacionaista). No caso chileno, a ideia de uma "retórica testemunhal" tornou-se, assim, um dos eixos centrais das discussões historiográficas ou das ciências nesse período.

Ou seja, no contexto do fim das ditaduras latino-americanas, a lembrança e os testemunhos se transformaram em fonte para a restauração de laços sociais e comunitários, como definiu o pensador francês Paul Ricouer. A memória em última instância seria a única guardiã de algo que "efetivamente ocorreu no tempo", fragmentada e pluralizada, se aproxima da história pela sua "ambição de veracidade". ${ }^{35}$ Como Sarlo nos lembra, o testemunho apresenta-se "(...) como instrumentos de

\footnotetext{
${ }^{32}$ SALAZAR, Historiografía y Dictadura en Chile..., p. 6.

${ }^{33}$ A maioria dos autores do período eram partidários políticos, líderes de movimentos e ex-ministros.

${ }^{34}$ SARLO, Beatriz. Tempo passado: cultura da memória e guinada subjetiva. São Paulo: Companhia das Letras, 2007, p. 17.

35 SILVA, Helenice. Rememoração/comemoração: as utilizações sociais da memória. Rev. Bras. Hist. [online]. 2002, vol .22, n.44, pp. 425-438. ISSN 1806-9347.http://dx.doi.org/10.1590/S0102- 
verdade (...)", para libertar “(...) os direitos reprimidos que devem se libertar (...)"36.

Desse modo, termos a razão pelas quais conceitos como "memória coletiva, enquadramentos, lugares da memória, esquecimento e testemunha já se tornaram lugares-comuns", mas que são constantemente demandados. Por sua vez, ainda segundo Sarlo, junto à demanda por esse tipo de narrativas, surgiram "(...) novas exigências e métodos que tendem à escuta sistemática dos "discursos de memória" "A chamada "guinada subjetiva" seria, portanto, um ponto de inflexão na teoria e na metodologia das ciências humanas em geral. Nesse contexto, a historiografia assume o papel de dar o suporte necessário para a busca de um passado que, para muitos, não foi experimentado. Constrói-se, assim, como definiu Grez a respeito dos textos históricos chilenos pós-ditadura, um conjunto de "verdades mínimas" sobre o passado. ${ }^{38}$ No quadro de reabertura política, desenhou-se um cenário de constantes disputas de memória sobre o passado militar chileno que denominamos, ao longo de nosso artigo como batalha de memórias. Como exemplificou Steve Stern em seu livro Luchando por mentes y Corazones: las batallas de la memoria en el Chile de Pinochet:

La "batalla de la memoria" nos permite ver un aspecto adicional de la vida chilena que es sutil pero central: el hacer y deshacer de la legitimidad política y cultural, aun cuando reine un violento gobierno del terror. En la lucha por las mentes y corazones de Chile, la cuestión de la memoria se volvió estratégica - política, moral y existencialmente - tanto durante como después de la dictadura. Así "la memoria" que en los años 80 se cristalizaba como una idea cultural clave, una nueva palabra importante y un campo de batalla arroja una nueva luz sobre la era total de la dictadura y de la democracia restrictiva, desdelos años 1970 hasta principios de la década $2000 .^{39}$

Esse campo conflitivo de memórias nos convida a ir além de dicotomias do antes e depois da ditadura militar. Nas palavras de Stern: "trazar las luchas políticas de la memoria nos invita a considerar no solamente la distancia y las tensiones entre las perspectivas de arriba hacia abajo y desde abajo, sino también las dinámicas interactivas más sutiles al interior de una historia de violencia y represión." ${ }^{40}$ Com um esforço coletivo e reforçando o processo de recuperação dos espaços, os historiadores da oficina "Nova história social" tiveram uma nova projeção com o fim da ditadura militar. Como exemplo, temos os trabalhos de Salazar com o texto Violencia política popular en las "grandes alamedas". Santiago de Chile. 1947-1987, de 1990, no qual o autor analisa a violência política popular em um período que se estende de 1947 até o fim da ditadura, e o texto La historia desde abajo y desde dentro (2003). Citamos também, dentro desse grupo, os livros de Julio Pinto Trabajos y rebeldías en la pampa salitrera -, e de Sergio Grez - De la regeneración del pueblo a la huelga general - sobre a história econômica e social dos mineiros da mina de sal do norte chileno, ambos de 1998. Em uma perspectiva diferente, mas buscando resgatar a historicidade do sujeito popular, citamos os trabalhos da historiadora Maria Angélica Illanes em sua obra Azote, salario y ley Disciplinamiento de la mano de obra em la minería de Atacama (1817-1850), de 1990.

A autora circunscreve a história do "movimento obrero" demonstrando uma lógica invertida com a "la lucha de los trabajadores por impedir justamente su proletarización, es decir, por evitar, la perdida de sus espacios de autonomia laboral y existencial" ${ }^{41}$. Ela reflete sobre a ideia do sujeito popular como sujeito social e acerca dos múltiplos significados que tem recebido ao longo dos anos na Nova história social. Para a pesquisadora, durante o período da Unidad Popular, a ideia era de povo na condição de corpo social que se transformou em sujeito ativo do processo de mudança, articulando-se com a política popular desenvolvida pelo governo. Ou como descreve "El cuerpo nuestro de cada dia: el

\footnotetext{
${ }^{36}$ SILVA, Rememoração/comemoração..., p. 39.

${ }^{37}$ SARLO, Tempo passado..., p. 34.

${ }^{38}$ GREZ, Escribir la historia de los sectores populares, p. 5.

${ }^{39}$ STERN, Steve J. Luchando por mentes y corazones. Las batallas de la memoria en el Chile de Pinochet. In: La caja de la memoria en el Chile de Pinochet. Santiago: Universidad Diego Portales, 2013, p. 23.

${ }^{40}$ STERN, Luchando por mentes y corazones..., p. 23.

${ }^{41}$ LLANES, María Angelica., Cuerpo y sangre de la política. La construcción histórica de las visitadoras sociales (1887-1940), Santiago, LOM Ediciones, 2007, 498p. Nuevo Mundo Mundos Nuevos [En ligne], Comptes rendus et essais historiographiques, mis en ligne le 10 mars 2008, consulté le 22 février 2016. URL: http://nuevomundo.revues.org/26702p.268 p. 90.
} 
pueblo como experiência emancipatoria en tiempos de la Unidad Popular", representada, portanto, num duplo sentido: o "ético-cultural" e o "político-prático".

De tal modo, o projeto de construção de uma ciência popular abraçado por Salazar continua, mas busca ampliar a história de "bajo pueblo", optando pela categoria ou conceito de "ciudadano", ou seja, daquele que luta por sua soberania, mas que esteve alijado do poder. A extensão desse conceito demonstra um esforço para abarcar uma sociedade e uma história mais completa ou, como melhor apresenta Illanes, o projeto de "baja ciudadania":

se expresa en la negativa a su proletarización económica y política y... en su resistencia al privilegio de clase... No tanto el 'desdén' del pueblo, sino la insolencia, la gallardía, el rostro alzado frente a frente y el desprecio del pueblo respecto a una clase que pretende construir sus privilegios sobre sus espaldas. Tanto su instinto como su conciencia 'igualitaria' ha sido y es el proyecto del ciudadano chileno. ${ }^{42}$

Em uma mesma compreensão, os historiadores da organização ECO (Educación y comunicación), coordenada por Mario Garcés, trouxeram para a historiografia a história do movimento de popular. Com o fim da ditadura, incursionaram em um novo caminho metodológico ao incorporarem em suas investigações as histórias de vida e histórias locais dos "pobladores", elaboradas com base na memória coletiva, e aos moldes de um caminho ainda pouco utilizado, a história oral. Como exemplo, temos Garcés em suas obras Tomando su sitio: el movimento de pobladores de Santiago, 1957 -1970, de 2002, e Historia de la Comuna de Huechuraba. Memoria y oralidad popular urbana, de 1997, nas quais incorpora e delimita a história do movimento popular chileno seguindo os relatos de vida dos pobladores. Com os depoimentos, o historiador consegue retratar as condições da classe trabalhadora fora do campo da produção e mais em seu universo de luta cotidiana, demonstrando, por exemplo, as estratégias adotadas dos pobladores para pressionar os governos no atendimento às suas reivindicações.

Em suma, como explicou Salazar, diante dos acontecimentos da ditadura e ocasionalmente do silêncio do período, o historiador precisa - não somente pela qualidade de cidadão, mas como profissional - orientar os atores sociais para que possam fundamentar eficazmente suas decisões históricas sobre o presente e o futuro. Isto é, "el historiador tiene que vérselas, además, comun futuro que está construyendo junto a "los actores sociales y la ciudadanía", al ejecutar "lavoluntad histórica (soberana) de la sociedad (o la mayor parte de ella)" produciendo hechoshistóricos "para el tiempo presente/futuro". ${ }^{43}$

A disciplina traçada por tais historiadores pode ser entendida aqui como um devir a sociedade, reconhecendo que tais "cidadãos" e o historiador podem em conjunto "produzir conhecimentos", além de "produzir feitos e processos históricos" 44 . O objetivo final, no entanto, não seria publicar verdades narrativas ou explicativas, mas colaborar "en la construcción de un poder social y cultural (popular o ciudadano)" com a capacidade não apenas para desfazer o modelo que domina na sociedade, mas também para propor outro e instalá-lo, por fim. Denota-se, assim, que a perspectiva "desde abajo" continua muito presente nessas publicações no período pós-ditadura e se converte durante décadas em uma linha estabelecida e cada vez mais seguida na academia. Ainda que a noção apareça mais detalhada ao incorporar os setores populares pela distribuição de poder, parece contraditório por negar a historicidade aos setores "detentores do poder".

Em outra linha, o historiador Alfredo Jocely-Holt, em seu primeiro livro La independência de Chile, pulicado em 1992 e apresentado como sua tese em Oxford, realiza uma espécie de crítica à visão da nova história social e aposta nos modelos da primeira historiografia chilena (Vicuña Mackenna, Barros Arana, Amunátegui) para explicar as rupturas da história chilena. Privilegiando seu interesse pelo o que denomina de "elite dirigente tradicional", Holt acredita que esses grupos têm historicamente desenvolvido elementos recorrentes no debate nacional como a ordem e o poder. Essas abordagens são mais enfáticas em sua obra El peso de la noche. Nuestra frágil fortaleza histórica, de 1997. Em suas palavras: "La sociedad tradicional persistió, no así la forma como se siguió legitimando dicha

\footnotetext{
${ }^{42}$ LLANES, Cuerpo y sangre de la política, p. 268.

43 SALAZAR, Historiografía y Dictadura en Chile..., p. 101.

${ }^{44}$ SALAZAR, Historiografía y Dictadura en Chile..., p. 105. 
sociedad"45. Para o autor, a nova história de Salazar apresenta uma estrutura precária ao desvencilharse das "memórias dos grandes feitos" e, ao mesmo tempo, reivindicava o retorno do gênero ensaístico:

La mejor historiografía en este país - la liberal del siglo XIX (Amunátegui, Vicuña Mackenna y muchos otros) y la conservadora en el XX - (Edwards y Góngora) produjo ensayos históricos y de esta forma influyó ampliamente en la sociedad. Lo mío, a lo más, pretende devolver a la historia el género que le ha sido siempre propio, para que vuelva a provocar y hacer pensar.

Como analisa a historiadora Sofia Correa Sutil ${ }^{46}$ ao comparar os dois historiadores e sua metodologia: "si Salazar escribe desde la inmersión en la historicidad del pueblo, Jocelyn-Holt lo hace desde su inmersión en el mito y la poesia" ${ }^{47}$.Segundo Sutil: "al contrario de como suele ser presentada en la historiografía social - no versa sobre hechos, sino acerca del sentido o significado de esos hechos" ${ }^{48}$. Entretanto, como demonstra a autora, ambos consideram que a produção historiográfica deve se expandir a amplos setores da sociedade chilena, entendendo a história como urgência vital para o período de transição no qual o país se encontrava. Assim descreve:

Comparten, pues, una común perspectiva historicista. Asícomo también la necesidad de dar sentido como historiadores, dar sentidos al presente desde el pasado, en el juego indisoluble de los tres tiempos históricos. Tienen en común la concepción de la historia como una disciplina humanizadora. La historia, para ellos, es una vocación, una forma devida, no un oficio que podría haber sido cualquier otro en vez. ${ }^{49}$

Essa breve revisão sobre algumas obras pós-ditadura não dá conta (e nem é nosso objetivo) de apresentar todos os textos publicados nessa época. Porém, poderíamos dizer, com base nos autores e nas obras citadas, que os anos iniciais de transição chilena catalisou alguns textos incubados durante o período militar e provocou novas linhas teóricas, como os textos de Jocelyn-Holt. Assim, o fim do período militar reanimou o debate sobre a disciplina e restituiu a fala de muitos textos silenciados. Entretanto, como demonstram os historiadores Julio Pinto Vallejos e María Luna Argudín em uma revisão sobre a historiografia chilena, para além dos espaços das editoras e das universidades - onde estava se defendendo a recuperação das memórias individuais e coletivas para tentar entender o período -, não ocorreram de tal forma na sociedade chilena. ${ }^{50}$

Como advertiram os historiadores, parte da sociedade chilena, ainda sob os efeitos do golpe e temerosa de perder a recém-restaurada democracia, preferiu esquecer para não reanimar esses fantasmas do passado. Ou seja, nas palavras dos autores: "concordaban en la conveniencia de dejar atrás un pasado plagado de divisiones para concentrarse en las tareas pendientes de la reconciliación y la modernización, estigmatizando a quienes sí insistían en la necesidad"51. Assim, uma atmosfera de triunfalismo e complacência atravessou o país durante a maior parte da década de 1990, fomentada pela normalização institucional e, em parte, pelo crescimento econômico, resignando o lugar do debate $e$ da pesquisa aos espaços da universidade e às vítimas sobreviventes. Além disso, as políticas de

45 JOCELYN-HOLT, Alfredo. El peso de la noche. Nuestra frágil fortaleza histórica. Buenos Aires: Compañía Editora Espasa Calpe, 1997, p. 43.

${ }^{46}$ SUTII.S.C. DOS HISTORIADORES, DOS HISTORIOGRAFÍAS DOS HISTORIADORES, DOS HISTORIOGRAFÍAS BALANCE HISTORIOGRÁFICO CHILENO. El orden del discu BALANCE HISTORIOGRÁFICO CHILENO. El orden del discurso y el giro crítico actual. rso y el giro crítico actual. Luis de Mussy (Editor), Ediciones Universidad Finis Luis de Mussy (Editor), Ediciones Universidad Finis Terrae, 2007. Texto disponível em: http://www.estudiosdelarepublica.cl/plugins/news/images/9 sofua correa balance historiogrufico pdf. . Acesso em 20 de maio de 2015

${ }^{47}$ SUTII.S.C. DOS HISTORIADORES, DOS HISTORIOGRAFÍAS..., p. 12.

${ }^{48}$ SUTII.S.C. DOS HISTORIADORES, DOS HISTORIOGRAFÍAS..., p. 33-34.

${ }^{49}$ MUSSY, Luis (ed.). Balance Historiográfico Chileno. El orden del discurso y el giro crítico actual. [S.1.]: Ediciones Universidad Finis Terrae, 2007.

${ }^{50}$ Concordamos com a proposição dos dois autores e tendemos a pensar, embora não tenhamos conseguido reunir provas suficientes de circulação e venda de livros das duas gerações de historiadores até agora apresentadas, que: os historiadores oficiais e "os de abajo" eram leitura de massa. Os de agora são para consumo interno, o que tem a ver com um movimento maior de distância entre academia e sociedade.

${ }^{51}$ PINTO; ARGUDÍN, 2006. 
estado para a transição chilena a democracia, tiveram um tom conciliatório. Privilegiando a adoção de medidas jurídicas e políticas que mantivessem o equilíbrio institucional restaurado, fomentando um silêncio quanto às atrocidades cometidas naquele período para superar o passado e seguir em frente.

Ocorre que, com o avançar dos anos 1990, diferentemente do ocorrido entre 1989 e 1990, o cenário político social chileno começou a mudar, como apontam Alberto Aggio e Gonzalo Cáceres Quiero. Segundo os autores, apesar das vitórias da Concertação nos anos seguintes, com as eleições de Patricio Aylwin e Ricardo Lagos e da relativa euforia pela reconquista da democracia, "o mal-estar dos cidadãos alcançou um ponto culminante entre 1998 e 1999" com o desencadeamento da crise asiática sobre o conjunto das massas populares e das classes médias. Esse processo que combinou com a sensação de frustação devido à persistência dos enclaves autoritários na constituição chilena, além da "falta de uma nova definição para o papel dirigente do Estado" e das "instituições que fortaleçam os atores sociais, a cidadania e a sociedade civil." Nessa esteira, o discurso reconciliador da memória institucional foi interrompido e desviado, mais de uma vez, pelas vozes das vítimas do regime ou por aqueles que se atreveram a questionar a imputabilidade dos criminosos da época em detrimento de uma homogeneização social do Estado.

Convencidos dos problemas de ordem traumática de não trabalhar a memória do regime militar pelo governo e dispostos a combater o que denominavam de "ansia del olvido", historiadores, coordenados pelos professores Mario Garcés, Pedro Milos Myriam Olguín e Julio Pinto, organizaram um grupo de trabalho interdisciplinar durante três meses para discutir sobre o tema da memória $e$ o exercício da reflexão coletiva no Chile da transição de combate a amnésia do período. Ao final, reuniram-se em um seminário, Memoria para el nuevo siglo, com a participação das principais universidades do país, em 1998. Em 2000, organizaram o livro de mesmo nome, compilando as principais reflexões teóricas do grupo. Sobre a convocatória e o encontro, Vallejos faz um balanço:

No son pocos los sectores de la sociedad chilena que se acercan al fin de siglo atravesados por una especie de ansia de olvido. Alimenta ese impulso, por una parte, la cercanía de tiempos traumáticos, y la permanencia de heridas sin cicatrizar. Para algunos, los golpeados y los derrotados, el olvido conjura el temor de que los traumas vuelvan a repetirse. Para otros, los causantes o cómplices de dichos traumas, el olvido permite seguir dilatando la negativa a reconocer errores y asumir responsabilidades. Para todos, en fin, el olvido - aunque sólo sea simulado - permite soportar las angustias de un equilibrio evidentemente inestable, en la esperanza de que el tiempo se encargará por sí solo de ir enterrando los dolores y diluyendo los rencores. ${ }^{52}$

Porém, em 1998, para além das fronteiras da academia, um acontecimento histórico tirou quase todo país do estado de latência e adentrou a arena pública de discussões sobre o passado chileno: a detenção de Pinochet, em Londres. No final daquele ano, ao pedir a extradição do ex-ditador Augusto Pinochet, que esteva em viagem à Inglaterra, o juiz espanhol Baltazar Garzón trouxe de volta ao debate a questão dos desaparecidos e dos crimes ocorridos ao longo da ditadura chilena. O juiz responsabilizou Pinochet pela violência cometida contra cidadãos espanhóis residentes no Chile durante a ditadura. Mesmo diante dos questionamentos dos advogados do ex-ditador, as autoridades internacionais deixaram claro que a questão dos direitos humanos não poderia ser discutida apenas em âmbito nacional.

O evento despertou não apenas as vozes reprimidas, como também grupos de segmentos médios e populares insatisfeitos com a política adotada pelo Concertação, sobretudo no que tange a não resolução dos entraves autoritários herdados do governo militar e as fortes crises econômicas no país. Com o "acontecimento-Pinochet", a história do golpe militar e as imagens de desaparecidos inundaram os canais da imprensa chilena. Todo esse cenário evidenciou as linhas tensões asiladas pela política de consenso e demonstrou o quão frágil era essa política de reconciliação, desencadeando reações nas ruas e uma pressão por um acerto de contas justo com o passado. Em resposta, o próprio ex-ditador redigiu uma carta aos chilenos com vistas a reinstalar a versão oficial que serviu para legitimar o golpe durante os vinte anos no poder. A tentativa era revigorar, mais uma vez, as teses que

${ }^{52}$ GARCÉS, Mario. Memoria para un Nuevo Siglo: Chile, Miradas a la segunda Mitad del Siglo XX. Santiago de Chile: LOM, 2000. 
justificaram a ditadura como dever de união nacional frente à ameaça marxista. O golpe teria sido, assim, segundo o ex-general, a "última reserva moral de la nación", como argumentou:

Las Fuerzas Armadas y de Orden no destruyeron una democracia ejemplar, ni interrumpieron un proceso de desarrollo y de bienestar, ni era Chile en ese momento un modelo de libertad y de justicia. Todo se había destruido y los hombres de armas actuamos como reserva moral de un país que se desintegraba, en manos de quienes lo querían someter a la órbita soviética. ${ }^{53}$

Esses discursos acabaram reavivando as leituras do golpe, suas origens e consequências. $\mathrm{O}$ jornal La Segunda ${ }^{54}$, por exemplo, publicou uma série de fascículos do historiador Gonzalo Vial referidos ao período conturbado de 1964-1973, apresentando teses cujas conclusões serviam à justificação histórica das ações pinochetistas. Essa retomada e tentativa de legitimar novamente as ações do período ditatorial, destinada a impor novamente uma "verdade histórica oficial", desencadeou uma resposta equivalente no meio historiográfico.

Foi nesse contexto que, em 1999, um grupo de onze historiadores ${ }^{55}$, encabeçados por Gabriel Salazar, decidiu publicar um Manifesto ${ }^{56}$ trazendo à luz novos aspectos da época da repressão militar. O documento foi concebido como uma ampla iniciativa que incluía a tarefa de "indagar, escrever $e$ promover iniciativas de recuperação da memória popular", ou seja, próxima do exercício da história social tão comentada ao longo do artigo. Nas páginas do Manifesto ficaram impressas não apenas as versões produzidas pelos historiadores acerca de seus embates com as visões de direita de Pinochet $e$ os historiadores ditos conservadores, no caso específico Gonzalo Vial, mas também inúmeras formulações sobre história e política. O documento serve como indicativo daquilo que o campo intelectual da historiografia chilena pensava acerca do dever da história e do ofício do historiador, além de questionar a política de memória do Estado. Como mencionado anteriormente, a sua publicação gerou um campo fecundo para o debate intelectual no Chile. Embora o texto não seja o mais indicado para representar as teses acadêmicas da historiografia chilena, mesmo que esses historiadores partilhem diversos elementos semelhantes em sua escrita, consideramos o Manifesto como um documento importante que guarda muito das propostas de historiografia do período. Precisamos manter em mente que o manifesto é uma interpretação desses intelectuais desde seu lugar como cidadãos e, portanto, questionadores dos deveres público e de seu lugar como profissionais. Lemos o documento primeiro como um manifesto, como deve ser, respeitando a sua linguagem imperativa $e$ subjetiva para chamar a atenção; e, em segundo, como um lugar de memória que carrega sentidos sobre o período da Unidade Popular e o regime militar. Logo, ele serve como fonte importante para compreender o clima do debate da historiografia recente do Chile.

Seu texto foi amplamente divulgado na imprensa e recebeu grande quantidade de adesões de historiadores tanto do Chile como de outros países. Entre eles, pesquisadores norte- americanos que replicaram o conteúdo do manifesto $e$, ainda, redigiram uma carta de apoio ${ }^{57}$ publicada no jornal $E l$ Siglo, nos dias 2 e 8 de abril de 1999. Em setembro do mesmo ano, o manifesto e os principais pronunciamentos que foram elaborados no período foram publicados em formato de livro de bolso. De certo modo, temos um texto que transita entre o conteúdo "científico" e o "político" e assim deve ser compreendido. Começando a análise pelas perspectivas do historiador Gonzalo Vial $e$ as repercussões geradas a partir de sua réplica ao texto do Manifesto. A violenta ação do golpe de setembro foi lida como "gesta nacional" necessária para impedir as crises e os perigos ideológicos dos

53 PINOCHET, Augusto. Carta a los Chilenos. Londres, 1998. Disponível em: https://es.wikisource.org/wiki/Carta_a_los_Chilenos,_de_Augusto_Pinochet. Acesso em: 3 nov. 2014.

${ }^{54}$ Os fascículos do jornal La Segunda foram publicados no final de 1998 e início de 1999.

${ }^{55}$ Nomes dos historiadores que assinaram o Manifesto: Mario Garcés, Sergio Grez, María Eugenia Horvitz, María Angélica Illanes, Leonardo León Solís, Pedro Milos, Julio Pinto, Armando de Ramón, Jorge Rojas Flores, Gabriel Salazar e Verónica Valdívia Ortiz de Zárate.

${ }^{56} \mathrm{Em}$ dezembro de 2004 e em setembro de 2011, foram publicados mais dois manifestos. Seus temas foram o Informe Valech e o Juízo da História sobre a ditadura militar, respectivamente. Os dois textos podem ser encontrados facilmente na internet.

${ }^{57} \mathrm{Nessa}$ carta, os historiadores assumem publicamente a responsabilidade frente à intromissão do governo americano em apoio ao regime ditatorial no Chile e ao silêncio da Casa Branca sobre a detenção de Pinochet em 1998. A carta pode ser encontrada em GREZ; SALAZAR, 1999. 
anos 1970, entendidos por Vial como fruto das "planificações globais" ou "ações globais do guevarismo".

Isto é, para o historiador, não cabia à história vincular a crise dos anos 1970 e acontecimentos históricos do passado mais distantes, porque a experiência do regime militar teria se limitado apenas ao período de 1960-1973 e, devido ao momento caótico instaurado, a ditadura foi a responsável pelo sucesso da recondução a uma democracia segura e estável. As extrapolações do governo como as violações e os crimes cometidos contra os direitos humanos, deveriam ser analisados separadamente. ${ }^{58}$ Sobre esse conjunto de percepções, os historiadores do Manifesto rebatem:

[...] las tesis históricas de Gonzalo Vial se refieren al periodo que permite explicar (y justificar) el Golpe de Estado de 1973, y están arregladas de modo de atribuir, a los afectados por este golpe (las facciones que implementaban 'planificaciones globales' y las que desestimaron la vía electoral-parlamentaria), la responsabilidad 'provocativa' de la crisis, por haber creado las condiciones de inestabilidad, ilegalidad y violencia que hicieron ineludible y necesaria la acción militar. ${ }^{59}$

[..] la lógica de la manipulación histórica es la misma en el caso de la Carta del exgeneral Pinochet y en el caso de los Fascículos del historiador Vial, pues coinciden plenamente en: la reducción del proceso histórico al período en que es posible justificar el Golpe de 1973; el silenciamiento de los procesos históricos estructurales y de la correspondiente responsabilidad de la oligarquía acumulada; la atribución de la crisis política de 1973 a la implementación de las reformas económicas y sociales; la ineludible y moralista intervención armada de los militares, y el acallamiento de los excesos faccionales cometidos por el gobierno militar después de $1973 .{ }^{60}$

Em síntese, para tais historiadores, não parecia viável "hacer historia política prescindiendo de la historia económica y social" ou prescindir dos "procesos soterrados y de larga duración". Assim, Vial estaria anulando os processos históricos estruturais da sociedade chilena e maquiando as responsabilidades da oligarquia e do imperialismo. O historiador Leonardo León aponta a "historiografia oficial" e a "historiografia conservadora" de Vial culpada por omitir "la historicidad de mapuches, desterrados, exiliados, bandoleros, sacrílegos y blasfemos, rotos insolentes e inquilinos arrogantes, libertinas y malévolas" ${ }^{1}$.

Segundo o autor, ao privilegiar narrar a história "de la gente decente", a historiografia conservadora deixou de lado "el lado oscuro y subterráneo de nuestros procesos formativos" ${ }^{62}$; portanto, longe de elevar o debate para a construção de uma sociedade verdadeiramente democrática. Para León, os historiadores possuem o dever ético de investigar a trajetória histórica de uma nação "que ha basado su estabilidad en la represión y marginalización de una parte importante de su población", ou seja, escrever a história sob a perspectiva de "baja cidadania". Como direciona o autor: "[..] debemos evitar que alguna vez vuelva nuevamente a correr la sangre de chilenos por nuestras calles. Y...también [evitar] que se intente transformar en héroes a criminales"63.

No tocante a essa proposta metodológica de recuperação da memória popular e sua reposição política, os autores deduzem sobre o passado da historiografía chilena: "lamentamos que en Chile actual las clases dirigentes están deduciendo la soberanía del texto constitucional de 1980, sin importar si esté fue producto soberano de una informada decisión popular, o de una imposición faccional de los poderes fácticos." ${ }^{64}$ Nesse trecho, notamos certos esquemas teóricos universais, principalmente no que toca a atribuição do papel da história e acerca da questão da soberania nacional: "nuestro parecer es que la cuestión de la soberanía y de los derechos humanos es la materia última, esencial, de que trata

\footnotetext{
${ }^{58}$ Não tivemos acesso aos textos publicados pelo autor para este artigo, mas pretendemos incluir o documento assim que possível. Para isso, utilizamos a perspectiva dos autores do Manifesto sobre a réplica do autor Gonzalo Vial.

${ }^{59}$ GREZ, Escribir la historia...;, Historiografía y Dictadura en Chile, p. 14.

${ }^{60}$ GREZ, Escribir la historia...; SALAZAR, Historiografía y Dictadura en Chile, p. 19.

${ }^{61}$ LEÓN, Leonardo. Maloqueros y conchavadores en la Araucanía y las pampas, 1700-1800, Temuco, Universidad de la Frontera, 1991.

, p. 97.

62 LEÓN, p. 98.

${ }^{63}$ LEÓN, p. 111-112.

${ }^{64}$ LEÓN, p. 19. 
la Historia" 65 . Portanto, o direito à soberania apresenta-se como um direito humano primordial, e cabe aos historiadores a tarefa de pesquisar os seus processos de conquista. A história seria, assim, não apenas o exercício dessa soberania, como a revalidação desses direitos. Essa dedução seria, a nosso ver, um modelo de intepretação geral. Desse modo, o Manifesto incluiu a defesa de um projeto de reparação e dever de memória às vozes silenciadas pela opressão nos diferentes tempos históricos do Chile. Como aludem:

[...] que la memoria social podía ser una manera muy importante de resistir culturalmente a la verdad oficial. Esa verdad arrogante y acrítica, y sin derecho a réplica de los vencidos, que se proclamaba diariamente por los medios de comunicación, controlados o dirigidos por adherentes o funcionarios del régimen militar. La historia, admitimos entonces, no era sólo el texto propuesto por el historiador, sino también memoria y oralidad, memoria e identidad, que de modo particular preservan los grupos populares en nuestro país. En efecto, a través de nuestras propuestas metodológicas las personas que participaban de los talleres, podían reconocerse con historia $[\ldots]^{66}$.

Com a análise do trecho, podemos perceber uma "vontade de verdade" sobre o estabelecimento do passado, aliado ao resgate de uma memória social. Seria um espaço de atividades voltadas para a função política de dever da memória, capazes de consolidar uma "réplica dos vencidos". Uma segunda preocupação do documento estaria ligada à função social da história e sua capacidade de fornecer um novo sentido para o passado e o futuro, como descrevem:

La historia no se solo pasado, sino también, y principalmente, presente y futuro. La historia es proyección. Es la construcción social de la realidad futura. El más importante de los derechos humanos consiste en respectar la capacidad de los ciudadanos para producir por si mismos la realidad futura que necesitan. No reconocer eses derecho, usurpar o adulterar ese derecho, es imponer, por sobretodo, no la verdad, sino la mentira histórica. Es vaciar la verdadera reserva moral de la humanidad. $^{12}$

Por fim, embora não seja um texto acadêmico, o manifesto ajudou a pensar sobre o texto a nova discussão que traz respostas para os questionamentos sobre a função da História e o dever de produzir resultados substanciais para o cidadão chileno $e$, ainda, discutiu o ofício do historiador e sua relação com a verdade.

\section{A função social da história e sua relação com a verdade, memória e justiça}

Uma das características da história do século XX ou das primeiras décadas do XXI é que estaríamos vivendo uma obsessão pela rememoração do passado e, ao mesmo tempo, a ausência ou elisão de memória coletiva. Tal conformação se configuraria por um alijamento crescente, quase uma ruptura, entre o espaço de experiência e o horizonte de expectativa, cujo resultado seria a suspensão do tempo histórico. Para Sergio Grez, essa descontinuidade na pós-modernidade europeia ecoa semelhantemente nos países latino-americanos após a queda das ditaduras militares, o que seria representado pelos seguintes termos:

la carencia de conciencia acerca de las raíces históricas de los grupos humanos; la sensación de estar viviendo un presente de tiempo muy corto, fugaz e inmediatista, y, correlativamente con ello, una incapacidad casi patológica de los individuos por proyectarse hacia el futuro más allá de su rol como consumidores. ${ }^{67}$

Como ressalta Sarlo, "lembrar foi uma atividade de restauração dos laços sociais e comunitários perdidos no exílio ou destruídos pela violência de Estado" ${ }^{68}$. Posto isso, o acontecimento do holocausto

\footnotetext{
${ }^{65}$ LEÓN, p.10.

${ }^{66}$ GREZ, Escribir la historia... e SALAZAR, 1999, p. 48.

${ }^{67}$ GREZ TOSO, Historia, política y ciudadanía en el Chile actual....

${ }^{68}$ SARLO, Tempo passado..., p. 45. 
e seus julgamentos instituiu um modelo para aqueles que, por meio de suas memórias, denunciaram os crimes praticados nas ditaduras da América Latina. Desse modo, o fim de regimes autoritários e a criação de Comissões da Verdade nos países latino-americanos comprovam que alguns dos ideais $e$ conceitos produzidos há séculos pela Europa continuam vivos. Ao mesmo tempo, apresentam, nesses países, uma necessidade social de recordar e redescobrir o passado coletivo, exigindo um conhecimento histórico diferente sobre a sociedade chilena contemporânea.

A luta política em torno da democracia reposicionou um tema caro para os historiadores chilenos no que diz respeito ao debate sobre o compromisso com a verdade e o que fazer com essa verdade. Procurando adequar os relatos de memórias individuais à veracidade histórica, o historiador elabora uma reflexão sobre a própria temporalidade. Assim com as querelas dos desaparecidos do período militar reativadas com a volta do Pinochet ao cenário público e à política de esquecimento engendrada pelo governo da Concertação, a historiografia chilena dominante nos anos 1990 e início de 2000, como observa Vallejos em sua reflexão sobre a historiografia chilena, apresenta um interesse geral em publicar "histórias de sínteses gerais" ou de "intenção interpretativa". Como exemplo, as obras Historia general de Chile ${ }^{69}$, por Alfredo Jocelyn-Holt, e os cinco volumes de Gabriel Salazar e Julio Pinto, Historia contemporánea de Chile ${ }^{70}$. Sobre essa última consideramos o parágrafo da introdução geral uma boa síntese das aspirações dessa historiografia:

Como material básico para la historia que, responsablemente, debemos construir. Problemas que persisten a través de muchos hechos y situaciones. Problemas de arrastre que ni la dirigencia representativa ni la ciudadanía soberana han podido (o no hemos podido) resolver. Problemas que, a la larga, terminan siendo una carga histórica creciente que rodea, aplasta y frustra la vida, sobre todo, del ciudadano corriente. Porque - ¿alguien piensa lo contrario? - la carga histórica más pesada del país la sostiene y absorbe la "mayoría inferior" de la sociedad civil. La que, por ello, está permanentemente forzada a repasar y repensar la historia, bajo todo su espesor objetivo y sobre toda su profundidad subjetiva, para seguir produciendo no sólo su vida y su futuro, sino también el futuro de la sociedad. Los héroes son estrellas fugaces que brillan más o brillan menos, la efigie de los estadistas puede recortar apenas el plano de una plaza, o todo el horizonte del pasado, pero es el ciudadano corriente el que, en la alta densidad de su anonimato, "vive" y "conoce" la historia según todas las urgencias de la humanidad. ${ }^{71}$

Como indicam os autores, mais que "narrar" o passado chileno, propõem-se a trabalhar os seus problemas históricos. Desse modo, Salazar tem defendido no campo historiográfico a construção de uma ampla e nova história social do Chile que faça mais do que narrar e analisar os acontecimentos, mas se comprometa a trabalhar os problemas históricos que a sociedade não resolveu, que permanecem "em torno de nós, não só como legados do passado, mas, especialmente como desafios, desafios e tarefas para as novas gerações"72. Em artigo ${ }^{73}$ publicado em 2007 para o livro Balance Historiográfico Chileno ${ }^{74}$, de Luis Mussy ${ }^{75}$, Salazar faz suas considerações sobre tal historiografia chilena. Sua percepção é que apesar da "Historia (o Memoria) oficial" de Chile ter tido maior espaço nas últimas décadas, a historiografia dos perdedores estaria em uma situação promissora, pois possui uma nova proposta epistemológica capaz de superar a dialética dos vencedores e vencidos. Sua nova característica mais peculiar, afirma o autor: "es que trabaja en los tres tiempos y por tanto recoge y se deja interpelar por la memoria popular como fuente de producción de conocimiento, y de producción

\footnotetext{
${ }^{69} \mathrm{JOCELYN-HOLT}$, El peso de la noche...

${ }^{70}$ SALAZAR; PINTO., 2002.

${ }^{71}$ SALAZAR; PINTO, p. 40.

${ }^{72}$ SALAZAR; PINTO, Vol. 1, p. 7-8.

73 "Historiografía chilena siglo XXI: transformación, responsabilidad, proyección". SALAZAR, Historiografía y Dictadura en Chile...

${ }^{74}$ MUSSY, Balance Historiográfico Chileno...

${ }^{75} \mathrm{O}$ historiador chileno Luis de Mussy organizou um ciclo de conferências na Universidad Finis Terrae, onde quatro historiadores Alfredo Jocelyn-Holt, Cristián Gazmuri, Gabriel Salazar e Miguel Valderrama foram convidados a apresentar uma interpretação sobre a historiografia chilena dos séculos XIX e XX. 
de hechos históricos, en los tiempos del presente y futuro." ${ }^{76}$ Ou visto por outro ângulo, "la sociedad es dueña de la historia", "la sociedad es la historia misma". ${ }^{77}$

É desse ponto, então, que se deriva que o trabalho do historiador precisa lidar com esses três tempos e, simultaneamente, com a sociedade como sujeito. Tem que decifrar o passado, colocar à prova seus acontecimentos $e$, sobretudo, trazer à tona seus sentidos projetados para o presente. Ou seja, a função social da história deve atuar em duas frentes: como instrumento de produção historiográfica e de produção histórica; e, assim, "colaborar en la construcción de un poder social y cultural (popular o ciudadano) con la capacidade necesaria no sólo para deshacerse del modelo de sociedad que domina, sino también para proponer otro modelo, y para construir su propia verdad histórica)". ${ }^{78}$ Esse novo caminho epistemológico da História Social mantém a memória popular como fonte de produção e conhecimento, mas também a compreende como fonte de produção de eventos históricos nos tempos presente, passado e futuro. Resultando, portanto, na justificativa da centralidade que a memória ganhou no trabalho historiográfico desse período.

Segundo o discurso desses autores, nos últimos anos, a história ocupou um novo lugar no Chile. Além de dar sentido ao passado, o trabalho do historiador guarda uma relação ativa com o presente $e$ se põe a serviço de oferecer respostas às perguntas que o passado impõe no presente. Como em toda batalha, os ecos da ditadura miliar no presente com as publicações de Vial e do Manifesto, por exemplo, e as políticas de reconciliação do Chile atual desencadearam um cenário de lutas e respostas na historiografia chilena. Desse modo, podemos dizer que o centro do debate da historiografia chilena recortado neste artigo, incluiu novas questões acerca da função da história e qual seu papel no quadro de eventos anterior, durante e pó ditadura e nesse sentido ajudou a configurar um novo sentido sobre o passado recente chileno.

\footnotetext{
${ }^{76}$ SALAZAR. Gabriel Vergara. La violencia política popular en las grandes alamedas. Santiago Chile 1947-1. 2 ed. Santaigo: LOM Ediciones. 2006, 356p. 


\section{RESUMO}

O objetivo deste artigo é analisar as principais obras escritas por historiadores chilenos sobre o período da ditadura militar do Chile (19731990) e identificar como a elaboração dessas narrativas sobre trauma, memória $e$ esquecimento deixou marcas na escrita da História do país. Para isso, pensamos a produção historiográfica chilena delimitadas em quatro etapas, nas quais buscamos destacar os principais autores de cada recorte proposto, bem como seus lugares de produção. $\mathrm{Na}$ primeira oferecemos uma contextualização com nossa leitura dos eventos que levaram ao golpe, de forma a fazer um quadro mais claro sobre acontecimentos mencionados pelos historiadores analisados e tentar demonstrar que o entrecruzamento do contexto com as narrativas produzidas não estão imunes às disputas de memória do passado narrado. Desse modo, apresentaremos três acontecimentos que consideramos decisivos para algumas mudanças metodológicas da historiografia chilena: o golpe militar e sua extensão, a vitória da Concertação e sua versão equilibrada do golpe e a detenção de Pinochet em Londres. O eixo de análise, portanto, é apresentar como a urgência do "dever de memória" sobre o passado traumático chileno ecoou estão nos trabalhos dos historiadores chilenos, especialmente no que diz respeito à abordagem estrutural, ao enfoque sobre a verdade, à função social da história e à justiça.

Palavras-chave: Ditadura; Chile; Historiografia; Memória.

\section{ABSTRACT}

The aim of this article is to analyze the main works written by Chilean historians about the period of the Chilean military dictatorship (1973-1990) and to identify how the elaboration of these narratives on trauma, memory and forgetting left marks in the writing of the country's history. For this, we think the Chilean historiographic production delimited in four stages, in which we seek to highlight the main authors of each proposed cut, as well as their places of production. In the first one we offer a contextualization with our reading of the events that led to the coup, in order to make a clearer picture about events mentioned by the analyzed historians and try to demonstrate that the cross-linking of the context with the narratives produced are not immune to the past memory disputes narrated. In this way, we will present three events that we consider to be decisive for some methodological changes in Chilean historiography: the military coup and its extension, the victory of the Concertación and its balanced version of the coup and the arrest of Pinochet in London. The axis of analysis, therefore, is to present as the urgency of the "memory duty" on the Chilean traumatic past echoed in the works of Chilean historians, especially with regard to the structural approach, the focus on truth, the social function of history and justice.

Keywords: Dictatorship; Chile; Historiography; Memory.

Artigo recebido em 31 jul. 2018.

Aprovado em 24 set. 2018. 